\title{
Congenital saccular cyst of the larynx: a case series
}

This article was published in the following Dove Press journal: International Medical Case Reports Journal

\author{
Ali Ismail Swaid \\ Department of ENT, Faculty of \\ Medicine, Jazan University, Jazan \\ 45I42, Saudi Arabia
}

Correspondence: Ali Ismail Swaid Department of ENT, Faculty of Medicine, Jazan University, PO Box 253I, Jazan 45।42, Saudi Arabia

Email aswaid@jazanu.edu.sa
Background: Congenital saccular cyst of the larynx is a very rare cause of respiratory obstruction in the neonatal period and in older children. It can be a potentially life-threatening condition. It can also present less dramatically later in childhood as a voice disorder. Early diagnosis and treatment are very important to avoid the high mortality associated with undiagnosed cases.

Subjects and method: I report here two cases of laryngeal saccular cyst with different clinical scenarios. The first patient presented immediately after birth with respiratory problems and the second presented later at an older age. Both patients were managed with endoscopic excision. Conclusion: Congenital saccular laryngeal cyst remains an important cause of respiratory obstruction in the neonate albeit being rare. It is amenable to treatment with minimally invasive procedures.

Keywords: laryngeal cyst, saccular cyst, neonatal stridor, child dysphonia

\section{Introduction}

Saccular cyst of the larynx is a very rare condition. When literature is reviewed, most of the articles are either case reports or limited case series. ${ }^{1-6}$ It could be congenital and present with symptoms immediately after birth or later during infancy and childhood or it can be acquired and present during adult life. ${ }^{3,7}$ Symptoms include respiratory obstruction, stridor, or change of voice. ${ }^{3,6}$ Here I report two cases of laryngeal saccular cyst with different clinical scenarios.

\section{Case I}

A full-term male neonate who was born by cesarean section at 39 weeks was noticed to have stridor immediately after birth. He was put on continuous positive airway pressure at age 45 minutes. At age 4 hours, he was intubated with endotracheal tube and put on mechanical ventilatory support because of worsening respiratory distress. The ENT was consulted 1 day after the patient birth. Examination revealed a morphologically normal looking neonate weighing $2.99 \mathrm{~kg}$. Diagnostic bronchoscopy revealed a right supraglottic compressible cystic mass obstructing the view of both vocal cords with normal subglottic area (Figure 1). CT scan showed a right laryngeal cystic mass which was $2.2 \times 1.5 \times 1.3 \mathrm{~cm}$ in dimension compromising the aerodigestive tract. The patient failed repeated attempts of weaning from mechanical ventilator and extubation of varying lengths throughout the 13 days following his birth. Informed consent was obtained and the patient was operated on at age 13 days. At operation, the patient was positioned and an operating laryngoscope was inserted and suspended. Xylocaine 1\% 
with adrenaline 1:200000 was infiltrated around the cyst. Small incision was made using a round knife and then the cyst was completely enucleated using a blunt hook. The cavity was partially closed using vicryl $5 / 0$. The baby was successfully extubated 48 hours after the procedure and remained stable thereafter with mild stridor. However, 2 weeks later the patient developed worsening stridor and became desaturated. He was reintubated and taken to the operation theater again. To our surprise the cyst appeared to have recurred. Re-excision of the newly formed cyst was done using the same procedure. The patient recovered well this time and he was extubated 2 days after the procedure. He was discharged from the hospital 2 weeks later. Follow-up as outpatient continued for more than 1 year and the baby remained symptom-free.

\section{Case 2}

A 4-year-old girl was referred to our clinic with a history of dysphonia and stridor since infancy associated with occasional attacks of sudden arousal from sleep. Her parents were anxious because their daughter's socialization appeared to be affected by this problem. Clinical assessment revealed an otherwise normal child with a clearly hoarse deep voice. Fiber-optic nasopharyngoscopy was done for her, which showed a rounded mass at the hypopharynx with normally looking mucosa obscuring the left vocal fold (Figure 2). CT scan showed a $3 \times 2.5 \times 2.2 \mathrm{~cm}$ cystic lesion in the right side of the larynx. The patient underwent successful endoscopic excision of the cyst using the same technique as in case 1 under general anesthesia. Follow-up for more than 2 years showed complete resolution of the symptoms without any recurrence.

\section{Discussion}

Congenital strider and respiratory obstruction can be caused by several conditions. These could be supraglottic, glottis, or subglottic conditions. Laryngomalacia is the commonest

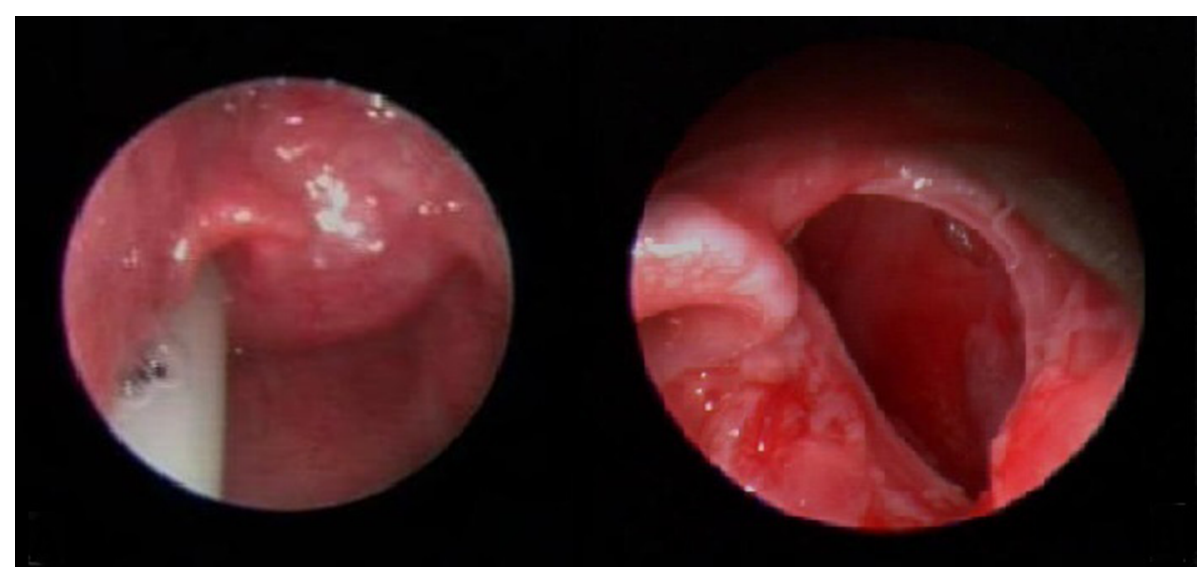

Figure I The saccular cyst before and after the first excision in case I.

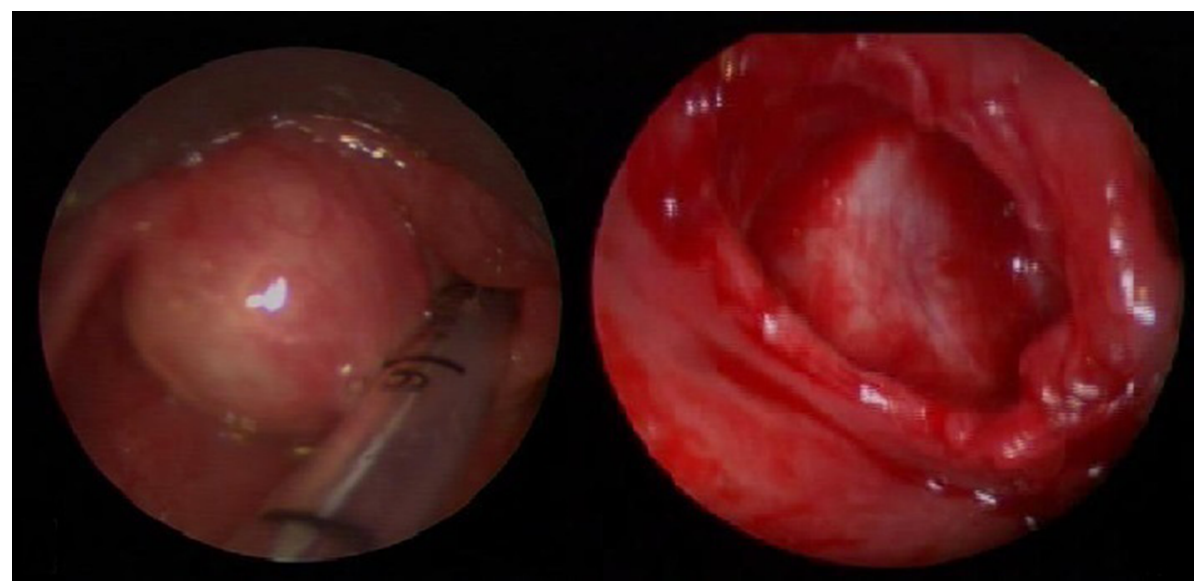

Figure 2 The cyst before and after excision in case 2 . 
condition. ${ }^{8}$ Other laryngeal causes include subglottic stenosis, vocal cord paralysis, laryngeal webs, hemangiomas, papillomas, and laryngeal clefts. Saccular cyst of the larynx remains a very rare cause of respiratory obstruction. ${ }^{3}$ Diagnosis could be delayed due to the large array of causes of respiratory obstruction in neonates. Kristensen and Tveterås claim that almost $50 \%$ of the reported cases are diagnosed at autopsy. ${ }^{9}$ In another study, Holinger found that the mean length of time from onset of symptoms to determination of the correct diagnosis by endoscopy was 4 months, varying from 1 day to 16 months. ${ }^{10}$ That is a long time for the diagnosis and hence treatment of a potentially life-threatening condition. Our first case went through a period of endotracheal intubation and ventilatory support for 13 days interrupted with failed trials of extubation of varying lengths before surgical intervention.

Several epidemiological studies targeted the pediatric population to detect the incidence of dysphonia among them. ${ }^{11-14}$ A prevalence ranging from $6 \%-12 \%$ was reported by these studies. It is often caused by voice abuse. ${ }^{15}$ The most commonly diagnosed lesions in the laryngoscopic examinations were vocal cord nodules and epidermal cysts. ${ }^{15}$ Congenital causes of dysphonia account for only $7 \%{ }^{16}$ Saccular cyst of the larynx remains a rare cause of dysphonia, in spite of the fact that dysphonia could be a common presenting symptom for it, especially in older children. In case 2 , the child was brought to our clinic after her parents noticed a significant effect of the problem on their daughter's socialization. This aspect of the problem was noted by some studies. ${ }^{17,18}$ It includes spectrum of psychosocial problems like sadness, anger, frustration, embarrassment, and negative perception by others.

Different procedures are being used to treat saccular cysts. Endoscopic needle aspiration, marsupialization, endoscopic extended ventriculotomy, and endoscopic radiofrequency ablation are all used in the treatment of this condition. ${ }^{3,19}$ Needle aspiration remains a temporary measure in lifethreatening respiratory obstruction as recurrence is very high after this procedure. ${ }^{6,20}$ Prowse and Knight concluded that single-stage endoscopic marsupialization is an effective means of treatment after treating a mix of ten patients with ductal and saccular cyst. ${ }^{21} \mathrm{CO}_{2}$ laser is used effectively for marsupialization and vaporization of the cyst lining., ${ }^{4,22,23}$ Kumar et al used radiofrequency ablation with success in a series of six cases. ${ }^{24}$ Kirse et al successfully treated a series of four patients aged 1-7 weeks with endoscopic extended ventriculotomy. ${ }^{19}$ An external approach is also used especially for large cysts protruding through the thyrohyoid membrane..$^{23}$ The best method of treatment is controversial as there are no studies comparing the different approaches, probably due to the rarity of cases. We managed our two patients with endoscopic excision. The first patient developed recurrence within a surprisingly very short time. It is difficult to conclude whether recurrence was related to the particular procedure that was used or to any other unforeseen factor.

\section{Conclusion}

Congenital saccular laryngeal cyst remains an important cause of respiratory obstruction in the neonate albeit being rare. It can be treated with minimally invasive procedures. Dysphonia in children should be well investigated and laryngoscopy should be regularly included in its assessment.

\section{Ethical approval and consent}

Written informed consent was obtained from the parents of both patients for publication of this case report and accompanying images. Ethical approval for the publication of this case was also obtained from the ethical committee of the Faculty of Medicine, Jazan University.

\section{Disclosure}

The author reports no conflicts of interest in this work.

\section{References}

1. Prasad KC, Ranjan RK, Agarwal S, Prasad SC, Bhat J. Congenital laryngeal saccular cyst: report of a case in an infant. Ear Nose Throat J. 2006;85(1):49-51.

2. Civantos FJ, Holinger LD. Laryngoceles and saccular cysts in infants and children. Arch Otolaryngol Head Neck Surg. 1992;118(3):296-300.

3. Tosun F, Söken H, Ozkaptan Y. Saccular cyst in an infant: an unusual cause of life-threatening stridor and its surgical treatment. Turk J Pediatr. 2006;48(2):178-180.

4. Kinnunen I, Klemi P, Grenman R. Saccular laryngeal cysts. Three case studies and review of the literature.ORL J Otorhinolaryngol Relat Spec. 2000;62(2):109-111.

5. Sennes LU, Imamura R, Frizzarini R, Hachiya A, Chagury AA. Congenital laryngeal saccular cyst. Braz J Otorhinolaryngol. 2012;78(3):137.

6. Zamfir-Chiru-Anton A, Gheorghe DC. Saccular cyst with atypical presentation. J Med Life. 2016;9(2):199-204.

7. Benoit C, Day T. Laryngeal saccular cyst. Diagn Ther Endosc. 2000;6(2):91-94.

8. Thurmond M, Cote DN. Stridor in the neonate: laryngomalacia. $J$ La State Med Soc. 1996;148(9):375-378.

9. Kristensen $\mathrm{S}$, Tveterås K. Congenital laryngeal cyst in infancy. A rare cause of life-threatening stridor. ORL J Otorhinolaryngol Relat Spec. 1986;48(3):150-155.

10. Holinger LD. Etiology of stridor in the neonate, infant and child. Ann Otol Rhinol Laryngol. 1980;89(5 Pt 1):397-400.

11. Lecoq M, Drape F. Epidemiological survey of dysphonia in children at primary school entry. Rev Laryngol Otol Rhinol. 1996;117(4):323-325.

12. Tavares EL, Brasolotto A, Santana MF, Padovan CA, Martins RH. Epidemiological study of dysphonia in 4-12 year-old children. Braz J Otorhinolaryngol. 2011;77(6):736-746.

13. Carding PN, Roulstone S, Northstone K, ALSPAC Study Team. The prevalence of childhood dysphonia: a cross-sectional study. $J$ Voice. 2006;20(4):623-630. 
14. Kallvik E, Lindström E, Holmqvist S, Lindman J, Simberg S. Prevalence of hoarseness in school-aged children. J Voice. 2015;29(2):e260.

15. Martins RHG, Hidalgo Ribeiro CB, Fernandes de Mello BMZ, Branco A, Tavares ELM. Dysphonia in children. J Voice. 2012;26(5):674. e17-674.e20.

16. Connelly A, Clement WA, Kubba H. Management of dysphonia in children. J Laryngol Otol. 2009;123(6):642-647.

17. Connor NP, Cohen SB, Theis SM, Thibeault SL, Heatley DG, Bless DM. Attitudes of children with dysphonia. J Voice. 2008;22(2):197-209.

18. Mornet E, Coulombeau B, Fayoux P, et al. Assessment of chronic childhood dysphonia. Eur Ann Otorhinolaryngol Head Neck Dis. 2014;131(5):309-312.

19. Kirse DJ, Rees CJ, Celmer AW, Bruegger DE. Endoscopic extended ventriculotomy for congenital saccular cysts of the larynx in infants. Arch Otolaryngol Head Neck Surg. 2006;132(7):724-728.
20. Narcy P, Bobin S, Manac'hY. [Laryngeal cysts in the newborn ( 9 cases) (author's transl)]. Ann Otolaryngol Chir Cervicofac. 1979;96(12): 881-888.

21. Prowse S, Knight L. Congenital cysts of the infant larynx. Int J Pediatr Otorhinolaryngol. 2012;76(5):708-711.

22. Massoth LJ, Digoy GP, Paul Digoy G. Flexible carbon dioxide laserassisted endoscopic marsupialization and ablation of a laryngeal saccular cyst in a neonate. Ann Otol Rhinol Laryngol. 2014;123(8): 541-544.

23. Abramson AL, Zielinski B. Congenital laryngeal saccular cyst of the newborn. Laryngoscope. 1984;94(12 Pt 1):1580-1582.

24. Kumar S, Garg S, Sahni JK. Radiofrequency ablation of laryngeal saccular cyst in infants: a series of six cases. Int J Pediatr Otorhinolaryngol. 2012;76(5):667-669.
International Medical Case Reports Journal

\section{Publish your work in this journal}

The International Medical Case Reports Journal is an international, peer-reviewed open-access journal publishing original case reports from all medical specialties. Previously unpublished medical posters are also accepted relating to any area of clinical or preclinical science. Submissions should not normally exceed 2,000 words or

\section{Dovepress}

4 published pages including figures, diagrams and references. The manuscript management system is completely online and includes a very quick and fair peer-review system, which is all easy to use. Visit $\mathrm{http}: / /$ www.dovepress.com/testimonials.php to read real quotes from published authors.

Submit your manuscript here: https://www.dovepress.com/international-medical-case-reports-journal-journal 